\title{
Bladder Outlet Obstruction Due to Bladder Leiomyoma - Case Report and Literature Review
}

\section{Daniel Savoldi Juraski, Lucas de Oliveira Claros, Ricardo Castellani de Mattos, Tomás Accioly de Souza and José Anacleto Dutra de Resende Júnior*}

Department of Urology, Lagoa Federal Hospital, Brazil

\section{Case Report}

Volume 3 Issue 3

Received Date: July 21, 2018

Published Date: July 30, 2018

*Corresponding author: José Anacleto Dutra de Resende Júnior, MD, PhD, Department of Urology, Lagoa Federal Hospital, Rua Jardim Botânico 501-6ªndar, Jardim Botânico, Rio de Janeiro, Brazil, Tel: +55 (21) 31115363; Email: joseanacletojunior@gmail.com

\section{Abstract}

Bladder Leiomyoma is a rare and benign disease with a variable clinical presentation. The use of imaging exams is necessary for both diagnostic confirmation and therapeutic programming. The objective of this work was to report the case of a patient diagnosed with bladder leiomyoma and treated at our service and to make a brief review in the literature about the subject. A 50-year-old female patient who presented with symptoms of the lower urinary tract, evolving to acute urinary retention and need for a bladder catheter. She was submitted to a magnetic resonance imaging (MRI) of the pelvis showing nodular oval formation of $3.7 \times 3.7 \times 3.1 \mathrm{~cm}$, located in the inferior vesical wall with apparent submucosal origin, bulging the external lower and lateral contour of the bladder and inseparable from the third proximal of the urethra. She was submitted to a transvaginal biopsy of the lesion guided by ultrasound (US) with histopathological report evidencing spindle-shaped cells with eosinophilic cytoplasm and cigar-shaped nuclei characterizing leiomyoma. Afterwards, she was submitted to laparoscopic excision of the bladder lesion requiring bladder suture with a bilaterally double J stent implant (previously to the abdominal access) and a bladder catheter implant after the procedure. The bladder catheter was removed on the 21 th postoperative day, with no voiding complaints. The double J stents were removed on the 45 th postoperative day.

Keywords: Bladder leiomyoma; Bladder outlet obstruction; Lower urinary tract symptoms

\section{Introduction}

Bladder leiomyoma is a rare disease, the most common benign mesenchymal tumor of this organ and corresponding to less than $0.5 \%$ of all bladder tumors [1]. It is more common in women $(75.6 \%)$ than in men $(24.4 \%)$ with a higher incidence between the fourth and fifth decades of life [2]. Its clinical presentation varies 
from absence of voiding symptoms (19-26.7\%) to storage symptoms (38-50\%) and emptying symptoms (24.3-49\%) $[2,3]$ and may be related to the location and size of the tumor [4].

The form of treatment is not consensus in the literature. Transurethral resection and laparotomy or laparoscopic enucleation with partial or total cystectomy may be treatment options and have variable recurrence rates $(11-22 \%)[2-5]$.

This article reports a case of a patient submitted to laparoscopic enucleation of a bladder tumor in our service and a brief review of the literature on the subject.

\section{Clinical Findings and Diagnostic Assessment}

A 50-year-old female patient, previously healthy, started in April 2017 symptoms of the lower urinary tract evolving into acute urinary retention in August 2017 with the need to use a late bladder catheter. She was submitted to a magnetic resonance imaging (MRI) of the pelvis in October 2017 showing a nodular oval formation with well defined limits and regular contours, with intermediate signal at $\mathrm{T} 1$ and $\mathrm{T} 2$, contrast hypocaptive and with restricted diffusion signals, measuring $3.7 \times 3.7 \times 3,1 \mathrm{~cm}$, located in the low bladder wall with apparent submucosal origin, bulging the external lower and lateral contour of the bladder and inseparable from the proximal third of the urethra (Figure 1).

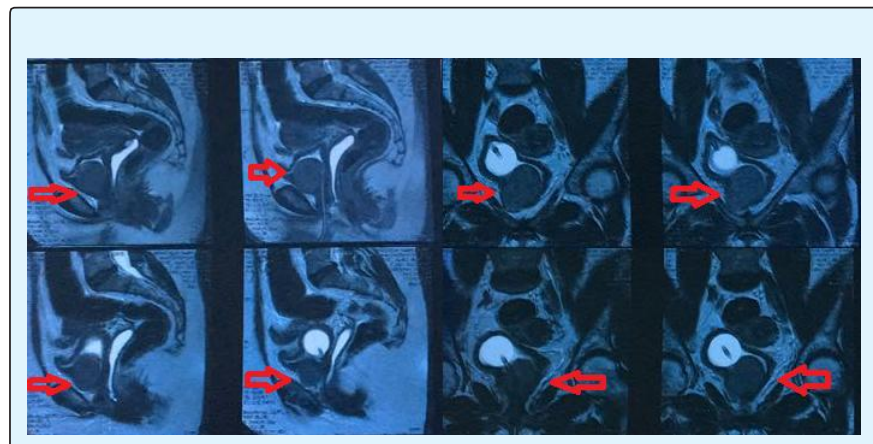

Figure 1: MRI identifying bladder neck lesion and presence of bladder catheter.

\section{Therapeutic Intervention}

Afterwards, she underwent a transvaginal biopsy of the lesion guided by ultrasonography with histopathological report evidencing leiomyoma.
Due to the findings, she underwent laparoscopic excision of the bladder lesion (Figures 2-4) requiring bladder suture in April 2018 and cystoscopy (Figure 2) for double J catheter implantation (before to abdominal access) and bladder catheter implantation after the procedure.

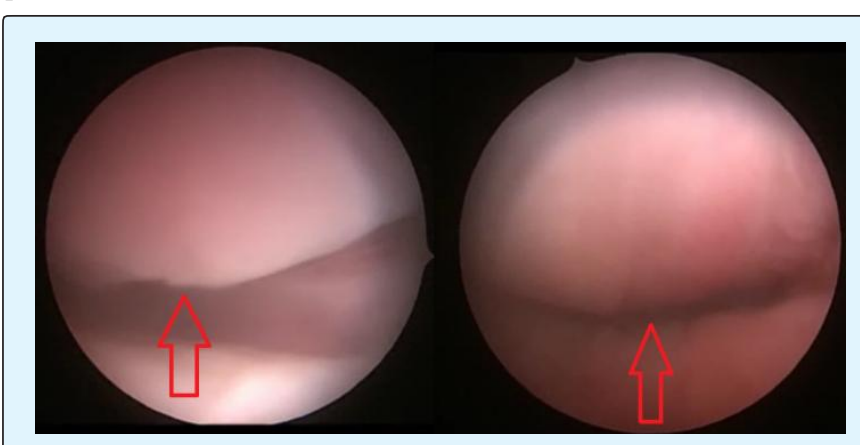

Figure 2: Anterior wall bulging in the bladder neck.

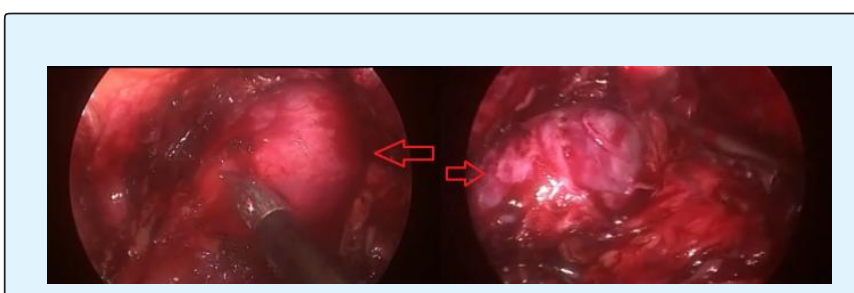

Figure 3: Bladder tumor seen by video laparoscopy.

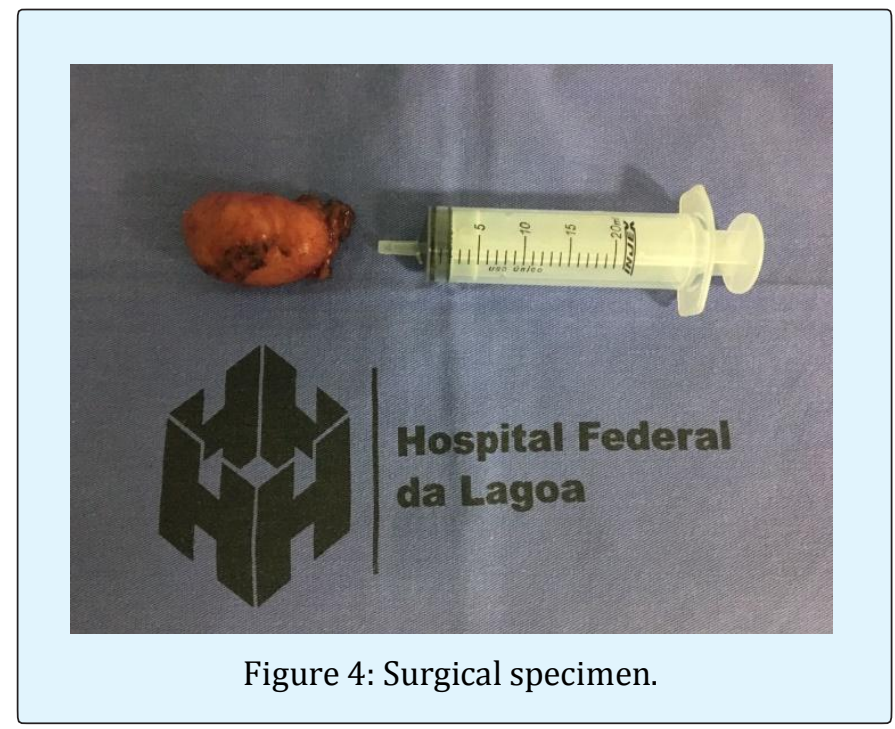

\section{Clinical Follow-Up and Results}

The histopathological report of the surgical specimen confirmed vesical leiomyoma. The microscopic examination revealed spindle-shaped cells with 


\section{Open Access Journal of Urology \& Nephrology}

eosinophilic cytoplasm and cigar-shaped nuclei, without pleomorphism or necrosis (Figure 5).

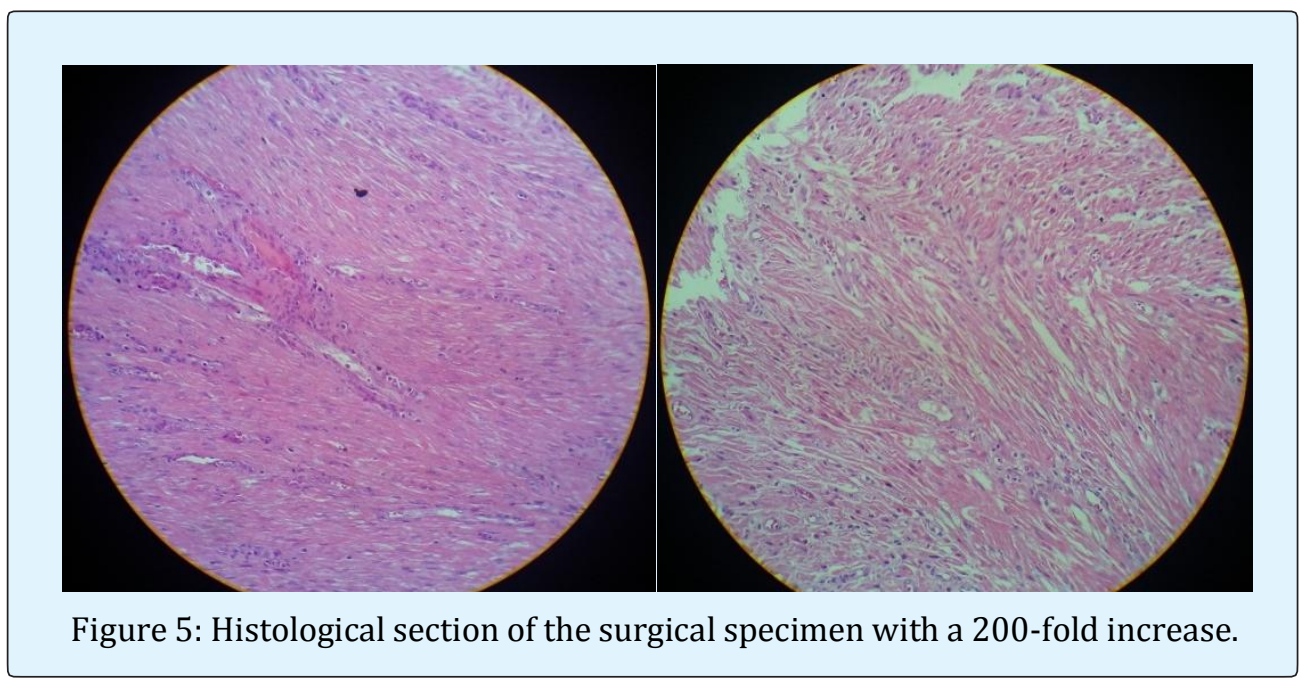

The bladder catheter was removed on the $21^{\text {th }}$ postoperative day, with no voiding complaints and the double J stents were removed on the $45^{\text {th }}$ postoperative day.

\section{Discussion}

Bladder leiomyoma is a benign and rare disease. Its clinical presentation is variable. About a quarter of cases do not show symptoms $[2,3]$, which may delay diagnosis and treatment. Usually tumors smaller than $3 \mathrm{~cm}$ are less related to lower urinary tract symptoms [6], but the location of the tumor may also be related to the appearance of symptoms such as the trigone, bladder neck and even urethra [7].

As in our case, screening can be initiated with ultrasonography (US) of the urinary tract, but magnetic resonance imaging (MRI) is the one with the highest specificity to characterize the lesion [8].

However, the diagnostic confirmation is made by the histopathological study, since the most solid tumors of the bladder are malignant neoplasms. The main histological characteristics described in the literature about leiomyoma are the presence of spindle-shaped cells with eosinophilic cytoplasm and cigar-shaped nuclei in the absence of aberrant changes such pleomorphism and necrosis $[4,9]$.

The patient in our case report had an image exam (MRI) with high suspicion of bladder leiomyoma, but we chose a histopathological confirmation by biopsy of the lesion before definitive treatment. The definitive treatment for bladder leiomyoma is surgical and there are several therapeutic modalities. Both open and laparoscopic surgical enucleation of the lesion is a plausible option for the case reported with several favorable outcomes described in the literature $[2,3,5,10]$. Transurethral resection has also shown good results mainly in minor lesions $[11,6,12]$.

\section{Conclusion}

Bladder leiomyoma is a benign and rare disease with predominance in women between the fourth and fifth decades of life. Its clinical presentation is variable and nonspecific, requiring imaging exams and histopathological studies to close the diagnosis.

Because it is a disease with an excellent prognosis, there are several forms of definitive surgical treatment described in the literature. The anatomical characteristics of the tumor such as size and location may influence the treatment.

\section{References}

1. Erdem H, Yildirim U, Tekin A, Kayikci A, Uzunlar AK, et al. (2012) Leiomyoma of the urinary bladder in asymptomatic women. Urol Ann 4(3): 172-174.

2. Silva-Ramos M, Massó P, Versos R, Soares J, Pimenta A (2003) Leiomyoma of the bladder. Analysis of a collection of 90 cases. Actas Urol Esp 27(8): 581-586. 


\section{Open Access Journal of Urology \& Nephrology}

3. Goluboff ET, OToole K, Sawczuk IS (1994) Leiomyoma of bladder: report of case and review of literature. Urology 43: 238-241.

4. Park JW, Jeong BC, Seo SI, Jeon SS, Kwon GY, et al. (2010) Leiomyoma of the urinary bladder: a series of nine cases and review of the literature. Urology 76(6): 1425-1429.

5. Chaker K, Sellami A, Ouanes Y, Zehani A, Dali KM, et al. (2018) Endovesical leiomyoma of bladder treated by enucleation: A case report. Urology Case Reports 16: 48-50.

6. Jiang XZ, Xu C, Zhang NZ, Xu ZS (2012) Influence of clinical characteristics and tumor size on symptoms of bladder leiomyoma: a pooled analysis of 61 cases. Chin Med J Engl 125(14): 2436-2439.

7. Streltsova OS, Kachalina OV, Yunusova KE, Molvi M, Kiseleva EB (2018) Urethral leiomyoma. Urologiia 1: 129-133.
8. Khater N, Sakr G (2013) Bladder leiomyoma: Presentation, evaluation and treatment. Arab J Urol 11(1): 54-61.

9. Caliskan S, Sungur M (2017) Bladder Leiomyoma. J Coll Physicians Surg Pak 27(3): 189-190.

10. Jamshaid A, Arshad Z, Zaidi SZ (2017) Leiomyoma of the urinary bladder. J Pak Med Assoc 67(9): 14471449.

11. Pompeo ACL, Sadi MV, Rosenblatt C, Tomé ALF, Pompeo ASFL, et al. (2005) Leiomioma vesical. Relato de quatro casos e revisão da literatura. Câncer Urológico e Suas Inter faces 2: 24-28.

12. Goktug GH, Ozturk U, Sener NC, Tuygun C, Bakirtas H, et al. (2014) Transurethral resection of a bladder leiomyoma: A case report. Can Urol Assoc J 8(1-2): E111-113.

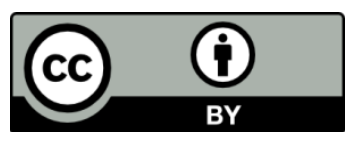

José Anacleto Dutra de Resende Júnior, et al. Bladder Outlet Obstruction Due to Bladder Copyright@ José Anacleto Dutra de Resende Júnior, et al. Leiomyoma - Case Report and Literature Review. J Urol Nephrol 2018, 3(3): 000143. 